\title{
Development of a best practice manual in wine tourism in Portugal
}

\author{
V. Woldarsky ${ }^{1}$ and L. Geny-Denis ${ }^{2}$ \\ ${ }^{1}$ WINTOUR Intern, ViniPortugal, R. Mouzinho da Silveira 5, 1250-165 Lisbon, Portugal \\ ${ }^{2}$ Responsable Licence Professionnelle Oenotourisme, University of Bordeaux-ISVV, 33882 Bordeaux, France
}

\begin{abstract}
Portugal has become a popular tourist destination in the recent years, encouraging the development of wine tourism. With increased demand and greater competition among wineries, managers must enhance wine tourism experiences to attract high-value customers in order to make wine tourism profitable and sustainable. One option is to have an appropriate set of standards to implement best practices in service, hospitality and overall experience. This research paper focuses on the development of a knowledge tool, in the form of a best practice manual. With the support of ViniPortugal, an inter-professional organization dedicated to promoting Portuguese wines, 63 wineries were selected to participate in this project, of which 47 confirmed their participation and provided the basis for the project findings. This paper will show the development behind a comprehensive best practice manual, based on literary theory, research, and real life evidence in wine tourism experiences in Portugal. The framework used for the best practice manual was an adaptation of the Knowledge-To-Action framework [1], which is divided into two sections, Knowledge Creation and Action Cycle. The project methodology is based on the Knowledge Creation format as follows: knowledge inquiry, knowledge synthesis and finally knowledge tool. By accumulating knowledge from different sources, the finished manual will be a powerful tool that provides management with practices, standards, and protocols in all areas of the wine tourism offer. The application, limitations and future use of the best practice manual are also discussed.
\end{abstract}

\section{Introduction}

In recent years, wine tourism has been on the rise and represents a robust segment of tourism. As tourists search for more authentic experiences, travelling to wineproducing countries and visiting wine regions is becoming more common. In addition, because wine tourism can include other tourism segments, such as cultural, heritage and gastronomy tourism, it appeals to more than just wine enthusiasts or wine experts and thus, attracts a large number of visitors.

Portugal has become a popular tourist destination in the recent years. In 2017, it received 12.7 million foreign visitors [2]. As the tourism flows increase, so too does the development of the wine tourism sector. Portugal has a diverse and dynamic wine industry, with a deep history. In recent years, Portuguese wines have gained international recognition in wine publications and have garnered accolades at various contests, resulting in greater visibility and attention in the wine market. The appeal of Portuguese wines goes beyond the product itself, and has crossed over to the viticultural landscape. Two Portuguese wine regions have gained UNESCO World Heritage Site status, the Alto Douro Wine Region (2001) and the Landscape of the Pico Island Vineyard Culture in the Azores (2004). Additionally, Porto, the city that has been historically linked to Port wine production, has also been named the European Best Destination three times since 2012 [3]. Thus, the link between wine and tourism is strong.

Wine tourism plays a significant role in the development of Portuguese tourism industry and also represents a new and valuable part of a winery's business [4]. Until recently, few Portuguese wineries offered wine tourism at their estate and it was usually in the form of providing accommodation. With the large number of tourist arrivals, many wineries have started to offer some sort of wine tourism to take advantage of this flow [5]. However, there is general uncertainty by wine producers about what wine tourism involves, what its purpose is beyond selling wine [6], and how to best use it to achieve desired results. It appears that very few wineries have mapped out a comprehensive strategy or plan for their wine tourism business, and most are guided by improvisation or imitation of other wineries' tourism offerings. While trial and error may have positive results by mere chance, this approach may also result in wineries offering inadequate services and experiences to visitors, leading to missed opportunities and a loss of investment. Further, as competition among wineries increases, consistently providing quality wine tourism experiences will be a winery's competitive advantage. Thus, winery managers will need to find a way to enhance their wine tourism experiences. One option is to have an appropriate set of standards that will provide winery owners and managers with the knowledge to 
implement best practices in service, hospitality and overall experience. ViniPortugal, an inter-professional association whose main activity is to promote Portuguese wines, carried out an innovative project to develop a best practice manual in wine tourism in Portugal.

\subsection{ViniPortugal: Scope of wine tourism project}

ViniPortugal is unique association comprising of eight professional organizations and representing approximately 300 wineries from the entire country, ranging from small and medium size companies to major industry players. Its mission is to promote Portuguese wines under the Wines of Portugal brand. It is by positioning the country brand over the regional ones that brings greater visibility and attention to Portuguese wines as a whole, and makes the country an attractive market in the wine trade. ViniPortugal carries out various marketing campaigns and promotional activities, both nationally and internationally. Currently, ViniPortugal does not use wine tourism to promote the Wines of Portugal brand nor is wine tourism a part of their corporate plan. Nevertheless, within the ViniPortugal framework there are approximately 60 wineries that offer wine tourism experiences. ViniPortugal recognizes the need for its associated members to offer high-quality tourism experiences in order to be competitive in this area, and to benefit both financially and for brand loyalty. This can be done by first identifying the key wine experience attributes presently available in wine tourism literature and research, and then identifying the problem areas and the best examples in "real life" wine tourism experiences. It is by collecting this knowledge that a tool can be designed containing guidelines, standards and best examples for winery management to implement.

Tasked with evaluating the quality of wine tourism offerings at the associated ViniPortugal wineries and then creating a best practice manual, this project involved four different stages. First, research on Portuguese wine tourism offerings, and literature review of best practices in wine tourism offerings and experiences. Second, the creation of an evaluation scheme to assess the quality of wine tourism offerings. Third, the application of the evaluation scheme at different wineries associated with ViniPortugal. Fourth, creating the best practice manual that could be used for practical application.

This paper will focus on the creation of a wine tourism best practice manual. It will demonstrate how a comprehensive resource manual - grounded in theory, research and real world evidence data - brings practical processes and tools to winery owners, managers and wine tourism departments to enhance the wine tourism offer.

\section{Tourism in Portugal}

Tourism in Portugal is flourishing. Since 2012, foreign tourist arrivals have constantly been increasing and Portugal is now one of the five most visited European countries [2]. In 2017, tourists in Portugal totalled 21 million, of which 12.7 million were foreign visitors, a growth of $12 \%$ from 2016 [7]. Revenue from tourism and travel account for 10\% of the GDP (2017) an increase of $2.7 \%$ from the previous year, and the sector employees 1 million (direct and indirect jobs).

Portugal is an attractive destination, benefitting from warm weather, beaches, diversity of landscape, historical and religious sites, cosmopolitan cities, singular gastronomy, and is generally inexpensive compared to other European countries. In addition, Portugal is considered a safe country to travel in, as there have been no terrorist attacks [2].

The inbound market is dominated by European countries, with the United Kingdom representing the greatest numbers of visitors (22.9\%), followed by German (13.9\%), France (10.6\%) and Spanish at 10.3\%. Statistical data also reveals that half of total visitors come to Portugal by road (55.6\%), followed by air (41\%) and the remaining by sea $(3.4 \%)$.

\subsection{Wine tourism in Portugal}

Foreign visitors consider Portuguese gastronomy and wines an attractive attribute of travel in the country [8]. As such, wine tourism is an important part in the national tourism plan of Turismo de Portugal (Plano Estratégico Nacional de Turismo (PENT). Nevertheless, national visitors still represent the largest market at winery visits (54\%), followed by English, French, Brazilian, Spanish and German visitors.

In 2014, Turismo de Portugal carried out a survey at wineries in Portugal that offer wine tourism [8]. The findings reveal important information for this project. First, that the tourism offer remains concentrated on the traditional tour and tasting ( $76 \%$ of survived wineries), offering very little diversity of experiences for visitors. Furthermore, because the majority of wineries are charging for experiences $(81 \%)$, it is necessary to make sure those experiences live up to the expectations of customers who will judge their worth [9]. Cross-selling experiences was only carried through by $33 \%$ of wineries surveyed.

Secondly, previous booking requirements makes it difficult for visitors to drop-in. As shown in the previous section, half of the international visitors arriving to Portugal enter by car and are of European origin. This means that they have increased mobility and can easily stop at a winery because of well-placed sign, yet only $26 \%$ of those surveyed are open to drop-in visitors.

Third, the employees at the wineries are not professionals in the tourism field. They may not be well trained (if at all) in service, hospitality, sales or wine education making them less effective to be able to communicate the correct information, deliver the winery story in a compelling way or close a sale.

Finally, and most importantly, the findings shows that there is a global interest in wine tourism, valuing its ability to create brand recognition (96\% of wineries agreed) and generate revenue $(62 \%)$.

\subsection{Wine tourism business}

Wine tourism offers huge potential for the winery owner. Offering wine tourism goes beyond simply meeting a demand. Extensive research by wine tourism scholars indicates that there are multiple benefits and gains 
from a well-developed wine tourism business $[4,10,11]$. The following lists shows the direct and indirect gains associated to a successful wine tourism business:

1. Increased direct-to-consumer sales

2. Repurchasing of wines in the future

3. Revisits to winery

4. Recommendation through word-of-mouth

5. Brand loyalty

6. Brand recognition

7. Increased brand equity

8. Destination loyalty.

A winery can choose to do wine tourism for financial reasons, to generate additional revenue by: selling wines direct to the consumer, to establish a rapport with a consumer to secure future purchases and repurchases, through the sales of tours, tastings and winery merchandise, and/or revenue generated by hospitality services such selling food at the winery restaurant. Wine tourism also provides the wine company with the opportunity to gain new consumers and strengthen their relationship with current consumers as wine tourism provides them with the opportunity to personally meet consumers [10].

Finally, a winery can develop wine tourism as a supplementary marketing strategy to build brand loyalty, brand recognition and word of mouth referrals [10]. The motivation to develop wine tourism by a winery owner can be for one of these reasons or a variety. Regardless, the winery owner must also understand why they are getting into this segment and finding the correct strategy to achieve the desired goals.

\section{Literature review}

Wine tourism is best understood as "visitations to vineyards, wineries, wine festivals and wine shows for which grape wine tasting and/or experiencing the attributes of a grape wine region are the primary motivation factors for visitors" [7]. A multi-layered and intricate sector of the tourism industry, for this study and the development of this project, our focus will be solely on experiences in the winemaking facility, during a winery visit. This can include visitations to vineyards and tastings, based on the above definition.

Presently, there is limited research related to implementing best practices at the winery or cellar doors. Some online material exists related to best practices in a certain area of the tourism experience, such as tasting room best practices. The United Nations World Tourism Organization has developed a prototype for wineries who want to develop wine tourism within a region, and the Winemaker's Federation of Australia provides detailed information and checklists for wineries looking to begin wine tourism business. Academically, the majority of research studies focus on different aspects of the wine tourism experience, including attributes that are most valued by visitors, and how these interact and affect their overall wine experience. In addition, there is also very limited information about how to apply these findings into every day practice. Nevertheless, the literature provides various concepts and relevant findings that can lay the foundations for the development of this project.

\subsection{Wine tourism attributes}

Wine tourism combines two different industries, wine and tourism, which means that the product being sold to the consumer is multifaceted, it is consumed at the moment of purchase, and has both tangible and intangible elements [11].

There are various features that make up the winery visit and multiple objectives to consider in the wine tourism business. Their importance and impact on the visitor's experience has been studied thoroughly in different research $[6,10,12]$. Of the tangible features, signage, cleanliness of the winery, building interior and ambience have been noted as having considerable impact $[13,14]$. Furthermore, Charters et al. [4] and Shapiro and Gomez [15] study how the various features and activities at tasting room affect consumer behavior and intentions to purchase. Charters et al. [13] also confirm that important factors for wine tourists are the winery and tasting room aesthetics.

Carlsen and Boksberg [6] state that in order to develop a tool and system of operations, there must be an understanding of the attributes that affect consumers and how they value these. Their study analysed 13 different attributes and found that service and the winery setting and surroundings were key attributes in the wine tourism experience. In terms of consumer value, their research indicated that consumers valued elements of the wine tourism experience that were emotional and epistemic. That is to say, experiences in wineries that provoked good feelings and also provided learning opportunities. Their findings also confirmed that wine quality and value-for-money were not considered important factors for wine tourists. Instead, service quality provided by knowledgeable and personable staff affected the winery experience the most. In addition, staff that is skilled in communicating wine information enhanced the factors most valued by consumers, emotional and epistemic. Carlsen [16] confirms this point, and states that in order to enhance these values winery staff should be well trained.

The research of Lee and McCole [11], also confirm that emotional and service values are the highest rated for consumer perceived winery value. Service quality, which involves professionalism of staff, wine knowledge, and ability to communicate dependable information, scored highest in their consumer ratings study. These are attributes that cause the visitor to feel good, relaxed, and enjoy the experience. In addition, they concluded that service value positively affected destination loyalty, which can impact the visitor's intention to revisit (behavioral loyalty) and repurchase (attitudinal loyalty). In addition, perceived value through service quality and emotional value result in word-of-mouth (WOM) recommendations, also confirmed by the research of Bruwer and Reilly [17].

Shapiro and Gomez [15] point to the importance of customer satisfaction for sales performance at a winery tasting room. Their study indicates that there are five main attributes of customer satisfaction: ambience, tasting protocol, service, retail execution, and tasting experience. Their study concluded that ambience and service being the most significant in customer satisfaction. As it has been noted previously, the quality of the wine did not play a significant factor in customer satisfaction, however, the relationship with winery personnel during the tasting experience impacted customer satisfaction. Their study 
also came to the conclusion that the level of customer satisfaction affects the behavioural intentions of the wine tourists. Contrarily, Lee and McCole [11] indicate that perceived value is created during the winery experience while satisfaction comes after the visit.

While much attention has been focused on service quality in wine tourism, Pine and Gilmore [9] claim that service is not enough to satisfy the demands of tourists. In fact, providing good service should be a standard, while creating memorable experiences is where a company will gain their competitive advantage. In their article, Differentiating Hospitality Operations via Experience, the goal of a tourism company is to provide experiences so that tourist stay longer, and spend more. This is done by creating memorable experiences that engage the visitors, as they explained, "Guests obtain a memorable experience when a company intentionally uses services as the stage and goods as props to engage individual customers in an inherently personal way" [9].

On the same note, Quadri-Felitti and Fiore [18] studied how the creation of memories affect customer satisfaction. As it has been seen in the Pine and Gilmore study that consumption experiences should include 4Es (education, esthetic, entertainment, escapism), they applied the 4Es to wine tourism and found that the 4Es positively affect the memories and satisfaction of the visitors. In particular, esthetics had the greatest impact in creating memories in wine tourism experiences and visitor satisfaction. This is another dimension that positively affects destination loyalty and intention to revisit. They highlight the importance of using sensorial elements to catch the attention of the wine tourist, such as viewpoints facing the vineyard area.

In another research done by Quadri-Felitti and Fiore [19], they focused on experience quality factors and then empirically studied their relevance in the winery environment. These quality factors were: environment, service providers, learning, entertainment, functional benefits and trust. This study confirmed once more that providing quality service is highly rated in terms of experience quality. Furthermore, that quality experiences have a positive impact on WOM, destination loyalty and satisfaction.

\subsection{Knowledge transfer}

The literary research shows that wine tourism is intricate and requires knowledge of the various components to make it successful. In addition to understanding these concepts, they must be applied correctly. However, this is where the gap lies, and despite the wealth of academic information available, in practice the theories and findings are rarely applied [20]. Cooper [20] lists various reasons why this occurs specifically within the tourism industry, but most important for this project, he states it is a result of a lack of trust between the "knowledge creators" and the knowledge receivers as they prefer information coming from their peers from "real life" cases. This is an important point to consider and shows that including the main agents and stakeholders in the development process is critical for the manual's application. To address this issue, a comprehensive model was found to be suitable and will be discussed in detail in Knowledge-to-Action Framework.
Applying these concepts requires continuous monitoring and managing to ensure their effectiveness. The problem lies in that many wineries do not assess their product and so are unaware of any problems or areas of improvement. They may only become aware of it when their overall visitor numbers or other goal indicates a downslide. Additionally, it could be as a result of a negative review or comment on social media, which can have a large impact [17]. Furthermore, even if a winery is succeeding in one aspect of the overall wine experience, such as providing excellent customer service, but failing in another aspect, then it makes the business less competitive. As Gilmore and Pine state, "Having nothing go wrong is not the same as having everything go right. Moreover, such an approach alone falls far short of intentionally creating personal memories- to entice guests to come back time and time again" [9].

\subsection{Methodology - development of best practice manual}

\subsubsection{Best practice manual objectives}

ViniPortugal has identified the following objectives as the main motivators to create and implement the best practice manual:

1. To set quality standards for Wines of Portugal wineries

2. To deliver professional service

3. To increase competitiveness of Wines of Portugal wineries

4. To resolve a problem in the wine tourism facility or setting

5. To achieve excellence in service by meeting or exceeding visitors expectations

6. To eliminate variations in quality for Wines of Portugal wineries

7. To improve the skills of wine tourism staff in service, sales and hospitality

8. To attract high-value tourists

9. To create a workforce with strong service culture

10. To assist winery management decision-making

11. To establish best policies and procedures for wine tourism experiences.

\subsubsection{Participants}

For the development of this project, ViniPortugal selected wineries that currently have wine tourism business at their estates, either in the forms of tastings, tours, accommodation or other. A total of 63 possible participants were contacted to communicate the objectives of the project and to confirm their participation. The total number of wineries that agreed to participate in this project resulted in 47.

These wineries are located in all of the wine-producing regions of Portugal, except in the Algarve region and the islands, and the tourism offers range from luxury experiences to basic tours and tastings. All wineries promote wine tourism on their webpage and some have partnered with travel operators focused on wine experience. It is uncertain whether the wineries offering wine tourism experiences have a wine tourism team and/or manager. 


\subsection{Knowledge-to-action framework}

A reference model used in the development of the best practice manual for this project is the Knowledge-ToAction Framework (KTA) used mainly in the healthcare industry [1]. The KTA Framework is divided into two sections, Knowledge Creation and Action Cycle. The first section, Knowledge Creation, involves the accumulation of knowledge through research, theory and evidence based practices. The concepts are synthesized in order to create a knowledge tool. The second section, Action Cycle, uses the knowledge tool in the form of guidelines, processes, etc. and applies it to different cases or problems, adapting and tailoring the guidelines depending on various factors. There are seven different phases within the Action Cycle, overlapping and non-linear phases, that feed back to the Knowledge Creation section. These are key points that address issues related to the use and application of the knowledge tool such as barriers and local context. While they are important to consider for future use of the manual, they go beyond the scope of this project. Nevertheless, the Knowledge Creation phases described below will be used to create the draft of the manual and various elements of the Action Cycle will be incorporated into the final version of the manual.

The reason why this model has been chosen as a reference for this project is because it highlights the importance of using more than just tourism theory and research to create a wine tourism best practice manual. By gathering information from a variety of sources and through different methods, it provides a comprehensive and solid backing to the guidelines and practices it recommends. For a wine tourism owner or manager, who may be sceptical or doubtful about its effectiveness, a wellfounded best practice manual will give them confidence in the recommendations provided. Other knowledge transfer methods are used in the tourism industry, however, none that involve the transfer of a broad range of knowledge into a knowledge tool that can be applied, adapted, tailored, monitored and re-applied once more in a full cycle of interactive components, like that of the KTA framework. Thus, the project methodology follows the Knowledge Creation format, as follows:

1. Knowledge Inquiry: This phase focuses on collecting information from primary and secondary studies in wine tourism.

2. Knowledge Synthesis: This phase focuses on collecting evidence based information from professional winery evaluations and self-assessments by winery personnel as well as consumer reviews.

3. Knowledge Tool: The final phase takes the data and observations of the previous phases and converts them into practical format.

\subsection{Knowledge creation}

\subsubsection{Knowledge inquiry}

As it has been seen in the literature review of this paper, wine tourism is multifaceted. There are various components that affect and influence the visitor experience and multiple points of interactions, not just between staff and visitor, but also the tangible and intangible elements of a visit [6]. After reviewing and analyzing the current research in wine tourism, the most important attributes were selected and categorized based on a visit from beginning to end. The categories are as follows:

1. Communication

2. Booking

3. Winery features

4. Staff

5. Experience.

These categories served to organize all points of interaction within this area of the wine experience and set the foundations for the creation of a winery evaluation tool, which will be described in the next phase of the Knowledge Creation.

The first category, communication, collected all information and research that highlighted the importance of online visibility, engaging with the visitor prior to arrival, functional website, information on wine tourism (both on and offline), social media presence, and form of contact between the winery and the potential visitor.

The second category, booking, focused on information pertaining to booking a visit, the various way of booking, the ease or difficulty in booking, and response time.

The third category, winery features, highlighted the various components of a winery that are important in terms of aesthetics, functionality, safety, ambiance and experience of the visit, and focused on the entrance and the estate, the winery/building interior, tasting area, wine shop, restrooms, and other areas in the winery.

The fourth category on staff grouped all information related to customer service and hospitality skills, presentation, professionalism, knowledge in wine, sales skills, and building a rapport with visitors (soft skills).

Finally, the last section focused on organizing data pertaining to the experience such as the 4Es of wine tourism (entertainment, esthetics, education, escapist, [18]), as well as the flow, design and logical behind wine experiences.

\subsubsection{Knowledge synthesize}

The next phase in the development of the best practice manual was obtaining information in the form of real life evidence. The methods used to obtain this data involved a professional evaluation of the wine tourism offer, analysis of consumer reviews, and winery management self-assessment.

\section{Professional winery assessment}

Based on the literary findings and the categorization of components of a winery visit noted above, a wine tourism evaluation scheme was created. The evaluation scheme focuses on the many points of interaction between a visitor and the winery features and winery staff during a winery tour. The evaluation scheme looks at key components of a visit from the moment of booking a visit until completion of the visit at the cellar door. This winery evaluation scheme was then applied during visits. Similar to mystery shopping program, the professional assessments involved evaluating the facility and the experience. The wineries being evaluated were the 47 that agreed to participate in this project with ViniPortugal.

Please note that for confidentiality reasons and because this project is still in progress with ViniPortugal, neither 
the evaluation scheme nor the list of wineries participating in this project can be provided. Following the winery visits, the information collected from the assessments was analyzed to identify the common problems areas among wineries and best examples.

\section{Consumer review assessment}

In this phase, we analysed the feedback by consumers on social media, specifically Google, Facebook, and TripAdvisor, and compared them to the findings from the Professional Winery Assessment. The purpose of analyzing consumer reviews is to identify the problem areas from the consumer's perspective, as well as the most memorable experiences. To avoid creating biases prior to a visit, the consumer reviews were analyzed after the winery visit and professional winery evaluation had been completed.

\section{Winery management self-assessment}

The last phase is a self-assessment by winery owners, managers or wine tourism managers. The self-assessment serves to understand the perspective of winery management in regards to their own wine tourism business, to identify areas they believe are key attributes of a wine experience, areas they believe require improvement or are lacking in some way. In addition, including participants in the project will build trust between the knowledge creations (ViniPortugal, and the researchers of this project), and create confidence in the manual, thereby, more likely to be accepted and applied in "real life" scenarios [20]. The self-assessment in the form of a qualitative survey, similar in scope and structure as the section of the Professional Assessment, but modified using the Likert Scale to allow for ease of answering and offering a range of perceptions.

At the end of the Knowledge Synthesis phase, all information and collected data was analyzed and organized. The most pertinent information, evidence, and cases were included in the draft creation.

Using these three methods to collect knowledge of a "real life" winery visit is an effective and valuable way to understand the wine tourism experience from the various perspectives. Backed by the theoretical and academic information, it provides a comprehensive basis for the knowledge tool, best practice manual.

\subsubsection{Knowledge tool: Best practice manual}

The final stage is the creation of the best practice manual as follows:

1. Draft

2. Review by a panel of wine and wine tourism professionals.

3. Final version.

The creation of the best practice manual consisted of:

1. Selecting the most appropriate, relevant and valuable topics based on the data analysis

2. Organizing each topic into chapters, which would be structured as follows:

a. Brief introduction of the topic and its importance, process and procedure in a specific area b. Provide checklists to follow, when needed (ex, tasting room items, physical winery items)

c. Provide recommendations and examples of application

d. A final and separate chapter dedicated to case studies, to show "Best Of" examples, and provide recommendations of implementation practices that vary in investment time and amount.

3. Panel Review: Once the draft has been completed, it will be reviewed by a panel of wine and wine tourism professionals for clarity, utility and to identify any gaps. Revisions based on the panel review will then be made.

\section{Discussion}

\subsection{Application}

Following the Action Cycle of the KTA framework, the best practice manual can be used in two common scenarios by winery management. One, to address a problem or inefficiency in the wine tourism product and use it to problem-solve through a "how-to" approach. Two, to use it as a guide to improve or enhance a certain area of the wine tourism experience. It can serve as reference book that staff or management can easily access to confirm the most adequate processes. To be most effective, it requires the direction and involvement of winery management to train, teach and lead the changes and/recommendations outlined. On a similar note, once new changes are implemented, it will require some monitoring by management staff to ensure its successful application.

\subsection{Future use}

The Wines of Portugal best practice manual can serve for more than just the application of guidelines and procedures during a winery visit. It provides ViniPortugal with the opportunity to create a committee or an assembly of wine and wine tourism professionals dedicated to improving and enhancing their wine tourism offer. Regular and ongoing meetings to discuss wine tourism issues, strategies, and report back on the application of best practice guidelines would give further confidence in the recommendations outlined in the manual and create a supportive community dedicated to making Portugal one of the best wine tourism destinations.

A best practice manual can also provide the framework for workshops and seminars, or similar to the "Enotourism Technician for the Sherry Wine Region", an educational workshop offered by the Sherry Council, ViniPortugal could adapt the material presented in the best practice manual to design a comprehensive training program and/or professional certification. An added program to the Wines of Portugal Academy, any winery completing the wine tourism course could earn a certificate of quality, which could be displayed at the winery like a TripAdvisor sticker. Moreover, a certification program that included wineries beyond the ViniPortugal wineries, open to anyone working in the wine tourism sector in Portugal, would strengthen the national wine tourism sector. 


\subsection{Limitations}

While the best practice manual is intended to have a positive impact on wine tourism practices and day-to-day winery operations, a few limitations have been identified. First of all, tourism is constantly changing in demand and in flows. At the moment, tourism data indicates continued growth for Portugal [2]. Wineries that rely solely on high volume tourism, instead of high-value tourists, may be tempted to disregard the guidelines of the best practice manual or findings that serve as its basis. On a similar note, local and cultural norms may also impede the application of the best practice guidelines, including resistance to change and varying beliefs about what service, hospitality and other wine tourism attributes mean.

The implementation and management of the best practice manual will require the involvement of winery owners, managers or facilitators, specifically those who have professional background in tourism, management, and hospitality. Training staff and monitoring the effectiveness of the guidelines will also take considerable time and dedication from management. Additionally, winery size and composition (i.e. staffing) vary and not all wineries may have the resources to train, apply, monitor the results and re-train as needed. Furthermore, its success (or failure) will be difficult to evaluate and may require another way of measuring outcomes.

Finally, using the best practice manual will also require adapting it based on the primary market or markets of the wine tourism unit. As shown in the previous chapter, there are five main inbound markets to Portugal, and each of these with different cultural expectations and perceptions of quality and service. While the creation of best practice manual is based on a comprehensive study of theoretical knowledge and real life scenarios, the best practice manual will need to be tailored to better serve those markets. Winery management must keep in mind how the best practice manual will match with their target market, and the requirements to meet their requirements and needs [21].

Despite these barriers, the survival of small and medium size wineries depends significantly on perfecting the wine experience for the visitor [6] and the application of the best practice manual will be highly recommended by ViniPortugal.

\section{Conclusion}

In conclusion, this paper has shown how the creation of a comprehensive best practice manual, based on theory, research, and "real life" evidence in wine tourism, brings practical and valuable processes to winery owners and wine tourism managers. The theory and research in wine tourism provide the background to understand the complex nature of wine tourism. By using this information to evaluate wine tourism experiences in practice, through a professional assessment tool, it brings to light other issues that may have not been considered. On the same note, understanding the areas of concern for winery owners and wine tourism managers and getting the perspectives on their wine tourism product in the form of a self-assessment, identifies areas of further study and research. With the knowledge accumulated from these different sources, it provides a solid and firm basis on which to design and create a best practice manual. The finished manual is a powerful tool that provides management with practices, standards, and protocols in all areas of the wine tourism offer in order to provide visitors quality experiences. It sets quality standards for Wines of Portugal wineries to deliver professional service, to resolve a problem in the wine tourism facility or setting, to improve the skills of wine tourism staff in the areas of service, sales and hospitality and empower the front-life staff. A best practice manual will also assist winery management in any decisionmaking regarding the wine tourism experience, having a reliable resource to verify their decisions.

By adopting the practices outlined in the best practice manual, a winery can benefit by increasing wine sales at the cellar door, encourage revisits to the winery, and increase the potential of recommendation through WOM. Creating genuine relationships with their consumer base can also build brand loyalty and destination loyalty. Thus, best practice manual would make wineries more competitive in the sector and attracting high-value tourists.

For ViniPortugal, being able to provide their associated wineries with a best practice manual would not only strengthen their wine tourism businesses individually, as explained above, but also collectively, by strengthening the Wines of Portugal brand. A successful outcome of the application of the best practice manual would allow ViniPortugal to promote wine tourism as part of its marketing strategy in the future, and would assist in their mission to position Portugal not only as a hotspot for wine trade but also for wine travel.

This project has been has developed within the Erasmus Mundus Master on Wine Tourism Innovation (WINTOUR), funded with support from the European Commission. Vinka Woldarsky was holder of an Erasmus + Scholarship assigned to WINTOUR programme. This publication reflects the views only of the author, and the Commission cannot be held responsible for any use which may be made of the information contained therein.

\section{References}

[1] I. Graham, J. Logan, M. Harrison, S. Straus, J. Tetroe, W. Caswell, N. Robinson, J. Cont. Ed Health Prof. 26, 13 (2006)

[2] Reuters. Portugal tourist arrivals spike 12 percent to new record in 2017 Available at: https://www . reuters.com/article/us-portugal-tourism/ portugal-tourist-arrivals-spike-12percent-to-new-record-in-2017idUSKCN1FY1S9 (14 February 2018)

[3] European Best Destinations https://www . europeanbestdestinations.com/

[4] S. Charters, J. Fountain, N. Fish, J. Trav. Res. 48, 122 (2009)

[5] T. Fernandez, J. Retail Cons. Serv. 31, 371 (2016)

[6] J. Carlsen, P. Boksberger, J. Hosp. Tour Res. 39, 132 (2013)

[7] Statistics Portugal, Est. do T. 2016, Ed 2017 Available at: https://www.ine.pt/xportal/ xmain?xpid=INE\&xpgid=ine_princindic

[8] TravelBI byTourism de Portugal "O Enoturismo em Portugal. Caraterização da oferta e da procura." Avaliable at: http://travelbi.turismode 
portugal.pt/pt-pt/Paginas/enoturismoem portugal2014.aspx (2014)

[9] J. Gilmore, J. Pine, Corn. Hosp. Quart. 43, 87 (2002)

[10] J. Carlsen, S. Charters (Eds.), Global Wine Tour: Res, mgmt and mktg (Wallingford, England: CABI, 2006), p. 47

[11] J. Lee, D. McCole, Tour Tr Res. Ass. Adv. Tour Res. Gl. 16 (2016)

[12] D. Quadri-Felitti, A. Fiore, Intl. J. Cont. Hosp. Mgmt. 28, 397 (2016)

[13] S. Charters, J. Fountain, M. Joanna, N. Fish, Intl. J. Wine Bus. Res. 20 (2008)

[14] E. Byrd, B. Canziani, Y. Hsieh, K. Debbage, S. Sonmez, Tour. Mgmt. 52, 19 (2016)
[15] M. Shapiro, M. Gomez, Intl. J. Wine Bus. Res. 26, 45 (2014)

[16] J. Carlsen, Intl. J. Wine Bus. Res. 23, 271 (2011)

[17] J. Bruwer, M. Reilly, Aus. NZ Wine Indus. Jour. 21, 43 (2006)

[18] D. Quadri-Felitti, A. Fiore, Intl. J. Cont. Hosp. Mgmt. 13, 47 (2013)

[19] D. Quadri-Felitti, A. Fiore, Intl. J. Cont. Hosp. Mgmt. 18, 3 (2012)

[20] C. Cooper, Knowledge Net and Tour (Routledge, Taylor \& Francis Groups, 2014), p. 62

[21] L. Hwang, A. Lockwood, Benchmkg: An Intl. Journ. 13, 337 (2006)

[22] B. Pikkemaat, M. Peters, P. Boksberger, M. Secco, J. Hosp. Mkg. Mgmt. 18, 237 (2009) 